\title{
Rational management of intracranial hypertension
}

\author{
St.M. Iencean ${ }^{1}$, A.St. Iencean ${ }^{2}$, M.R. Gorgan ${ }^{3}$ \\ 1"Grigore T. Popa" University of Medicine and Pharmacy Iasi \\ ${ }^{2}$ Emergency Hospital "N. Oblu” Iasi \\ 3"Carol Davila" University of Medicine and Pharmacy Bucharest
}

The treatment of intracranial hypertension depends on the type of intracranial hypertension and on the developmental stage of the illness. The treatment is first of all an etiologic one in order to remove the cause that has caused the intracranial pressure increase; simultaneously, there is an attempt to stop the pathogenic mechanisms that impact on the nervous structures, and a symptomatic treatment is applied in order to reduce the intensity of the clinical syndrome.

The term of etiologic treatment refers to the etiology of the intracranial hypertension, that is to the immediate cause that generates the intracranial pressure increase: for instance, in the case of a cerebral metastasis leading to $\mathrm{ICH}$, the name of etiologic treatment is given to the action of metastasis extirpation, and it has no connection to the etiology and the therapy of the original neoplasia $(1,2,3,4$, 15).

The intracranial hypertension treatment can be complex by combining three therapeutic methods used concomitantly or successively, or only the pathogenic therapy and the symptomatic one are used, depending on the clinical stage and the paraclinical explorations.

The type of intracranial hypertension establishes the treatment that must be applied:

1. the treatment is etiologic in:
- expansive intracranial processes: cerebral tumors, intracranial hematomas, cerebral abscesses, hydatid cyst, etc., in the case of parenchymatous intracranial hypertension,

- hypertensive encephalopathy in the case of vascular intracranial hypertension,

- thrombosis of intracranial vessels, venous or arterial, in the case of vascular intracranial hypertension,

- CSF circulation disorders due to the existence of a ventricular or paraventricular tumor with the occurrence of an obstructive hydrocephalus,

- CSF resorption disorders in acute meningitis.

2. the pathogenic treatment is applied in:

- the ICH cases with known etiology, which are mentioned above, in order to stop the development of the pathogenic mechanisms that have already started,

- the parenchymatous intracranial hypertension due to posttraumatic brain edema, hypoxic brain edema caused by secondary posttraumatic cerebral ischemia or in the case of sub-arachnoid hemorrhage, general intoxications with neurotoxins (endogenous or exogenous), etc.

- the vascular intracranial hypertension due to cerebral venous thrombosis, thrombosis of superior sagittal sinus with a decrease in the venous drainage and the blockage of the CSF absorption, or in the case of the secondary ischemic brain edema 
in the ischemic stroke caused by the occlusion or the stenosis of the great cerebral vessels,

- intracranial hypertension due to CSF dynamic disorder

- idiopathic intracranial hypertension especially in order to block the development of certain complications depending on possible pathogenic mechanisms.

3. symptomatic treatment:

- all the cases of intracranial hypertension, when the etiologic and/or pathogenic therapy is applied, benefit from the symptomatic treatment, depending on the presented symptomatology,

- in idiopathic intracranial hypertension. $(1,2,15,27,28)$

Based on the manifested clinical syndrome, there may be several situations that correspond to the evolutionary stages of intracranial hypertension:

- the patient is conscious and the cerebral exploration reveals a lesion that may cause the development of an intracranial hypertension syndrome - the treatment is etiologic and it addresses the lesion that may cause $\mathrm{ICH}$,

- the patient is conscious with incipient ICH signs, therefore with a compensated ICH syndrome, with or without focal neurological signs - the treatment is etiologic, pathogenic and symptomatic,

- the patient is in a critical condition, with consciousness disorders, with a decompensating ICH syndrome or in a coma due to the decompensation of the intracranial hypertension - the treatment is etiologic, pathogenic and symptomatic, and it is applied immediately.

\section{Therapeutic recommendations}

\section{Etiologic treatment}

I. If there is an expansive intracranial process that caused the intracranial hypertension syndrome, the etiologic treatment consists in the surgical intervention for the lesion removal.

In numerous situations, the neurosurgical techniques allow the ablation of that particular expansive intracranial process:

- the extirpation of the cerebral tumors is complete or partial, depending on the tumor location relative to the eloquent nervous structures, and depending on the benign or malign character of the neoformation. The removal of the neoformation makes the supplementary endocranial volume disappears as a first moment in the development of the intracranial hypertension, as well as removing the compressive effect on the CSF circulation paths and the edematous effect on the adjacent nervous parenchyma. (Figure 1)

- the expansive traumatic lesions, with or without a traumatic brain edema, are surgically solved by the evacuation of the traumatic hematomas, the removal of the edematous cerebral dilaceration, etc., (Figure 2)

- other expansive intracranial lesions, non-tumor or non-traumatic lesions, such as the cerebral abscess, the dural empyema, the hydatid cyst, etc., are surgically solved, usually by a complete evacuation. $(4,6,8)$

II. In the case of hypertensive encephalopathy, the etiologic treatment is the treatment of the hypertensive crises with a gradual, but fast enough, return, to normal values of the blood pressure, concomitantly to the brain edema decrease and the clinical improvement of the $\mathrm{ICH}$ syndrome.

III. In the case of the vascular intracranial hypertension, due to cerebral 
venous thrombosis, thrombosis of superior sagittal sinus, etc., anti-thrombotic and anticoagulant substances may be used.

IV. In the ischemic stroke caused by the occlusion or stenosis of the great vessels, substances with fibrinolytic action may be used: intravenous thrombolysis, fibrinogen degrading enzymes, etc. The thrombotic occlusion of the Sylvian artery can benefit from an extra-intracranial anastomosis with the superficial temporal artery. The carotid endarteroctomy and the angioplasty, with the mechanic removal of the sanguine coagulum or with the installation of an arterial stent, have been used in emergency cases, but certain procedures are presented especially as prophylactic surgical treatments for the cerebral stroke in patients with repeated transitory ischemic cerebral vascular accidents.

$\mathrm{V}$. The intracranial hypertension, due to CSF resorption disorders, secondary to an acute meningitis benefits from the etiologic treatment of the bacterial meningitis, which decreases the meningeal inflammation and reduces the changes in CSF resorption.

VI. In intracranial hypertension of acute liver failure with endotoxic etiology, the etiologic treatment consists of performing a hepatic transplant. The decision on the performance of the hepatic transplant is made based on the neurological prognosis monitoring the intracranial pressure in the fulminating case of a hepatic failure of a degree $\geq 3$, (West Haven Criteria of Altered Mental Status In Hepatic Encephalopathy).

VII. In the intracranial hypertension of the posterior reversible encephalopathy syndrome (PRES) with a non-hypertensive etiology, due to the neurotoxic action of certain immuno-suppressors or cytostatics, the treatment is etiologic, and it consists of interrupting the causing medication, with the progressive improvement within a few days.
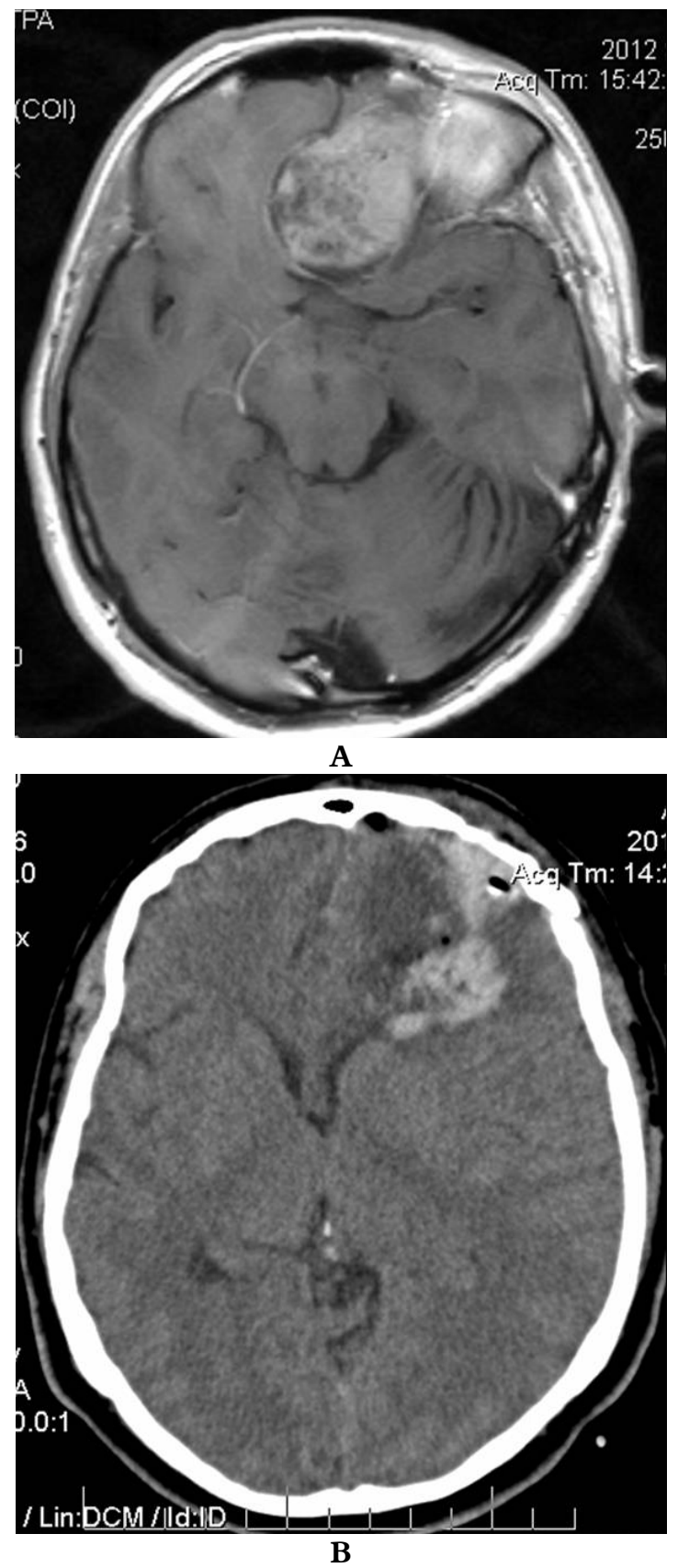

Figure 1. Olfactory groove meningioma: MRI preoperative (A) with secondary intracranial hypertension and postoperative (B) image with normal cerebral ventricles 


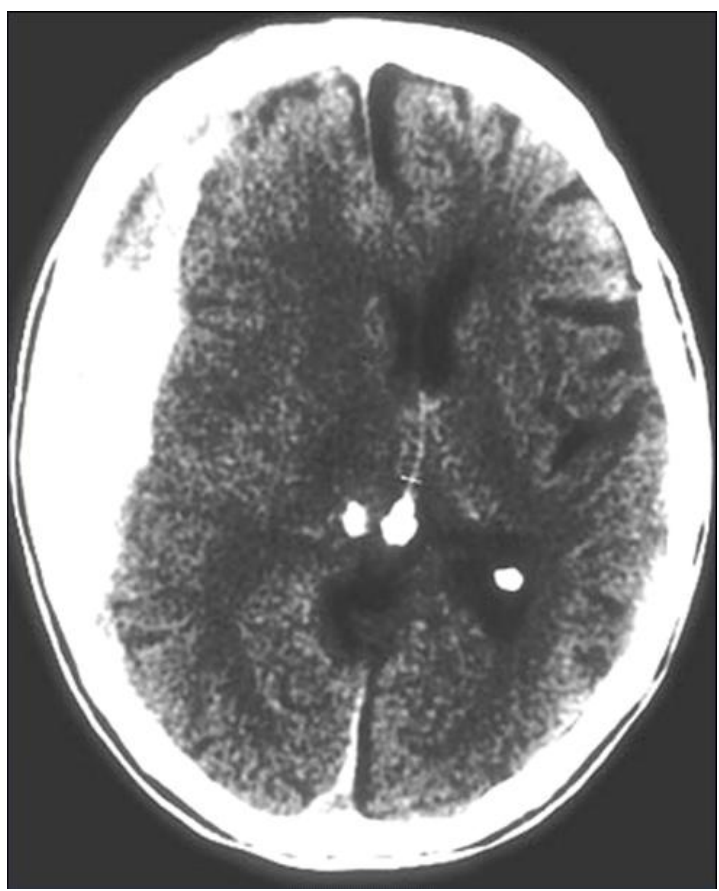

Figure 2. CT image of right subdural hematoma and secondary intracranial hypertension

\section{Pathogenic treatment}

The pathogenic treatment is used in all types of intracranial hypertension in order to stop the pathogenic mechanisms by means of which various causes bring about the intracranial pressure increase, and which cause the compensating capacities of the endocranial pressure increases to be exceeded. $(3,4,9,19,20,22)$

The purpose of the pathogenic treatment is:

- to act on the development of the brain edema, and once this has occurred, it must be reduced by medication therapies or there must be an attempt to decrease the effect of the neoformation or of the perilesional brain edema on the rest of the nervous parenchyma by surgical decompression,

- to prevent the occurrence of internal hydrocephalus and, in the case of an already existing obstructive hydrocephalus, to decrease the volume of the ventricular CSF,
- to prevent endocranial circulatory disorders or to bring back to normal values the already affected cerebral sanguine circulation, in order to stop the development of the cerebral ischemia,

- in the case of certain signs that announce a complication, to stop the development of that particular process (decompression of the optic nerve in idiopathic ICH in order to stop the evolution of cecity, etc.),

- before the occurrence, or at the first signs of intracranial hypertension decompensation through the appearance of a cerebral hernia, to try various maneuvers for the protection of the nervous parenchyma by using methods such as ventricular drainage, sub-temporal decompressive craniectomy, craniectomy of posterior cerebral fosse with the excision of the posterior arch of the atlas, etc. $(9,23$, $26,30,31)$

\section{Symptomatic treatment}

The symptomatic treatment is necessary in most cases of intracranial hypertension in order to decrease the intensity of the symptoms until the etiopathogenic therapy comes into effect, and then concomitantly with it. Antalgics, antiemetics, antivertigos, anticonvulsants, antithermics, sedatives, etc., are used, depending on the existing symptomatology. $(1,2,21)$

\section{Therapeutic schemes in intracranial hypertension}

\section{Treatment of the brain edema}

The pathogenic treatment of the brain edema depends on the type of edema:

- the cellular cerebral (cytotoxic) edema occurs due to the intra/extracellular osmotic pressure disequilibrium, with an intact brain-blood barrier, and it is reduced by 
diuretics;

- the hydrostatic extracellular brain edema in hypertensive encephalopathy is caused by the increase in the hydrostatic pressure from the cerebral capillaries secondary to a severe AHT, and it is produced by an ultra-filtration mechanism with an intact brain-blood barrier;

- the oncotic (vasogenic) extracellular brain edema represents a severe alteration of the brain blood barrier (open brainblood barrier), it has a peri-tumor development or in other lesions by through a vasogenic mechanism, and it responds favourably to corticosteroids;

- the mixed brain edema, cellular and extracellular, is the most frequent type of brain edema; the typical features occur from the start in the case of the traumatic brain edema.

Diuretics and corticosteroids are used in order to decrease the brain edema. $(2,5,7$, $8,10)$

The mannitol is an osmotic diuretic, and it is used in a dose of $0.25-1 \mathrm{~g} / \mathrm{Kgc}$ intravenously; the effect occurs after $10-$ 15 minutes, it lasts for approximately two hours and it may be repeated after 6 hours. It is efficient in the case of the brain edema with intact brain-blood barrier. The administration of larger doses does not reduce the intracranial pressure further, but there is a longer period of action. The mannitol must be carefully administered in order not to increase a hematoma by decreasing the volume of the parenchyma with an edema around. During the mannitol therapy, one must verify the serous osmolarity, which must be maintained between $300-315$ mOsm / L.The osmolarity can be calculated, and must be maintained below $320 \mathrm{mOsm} / \mathrm{L}$.

The classical belief is that mannitol can be administered in sufficiently large doses, taking into account the serous osmolarity, in order to prevent a possible secondary renal insufficiency. Recent studies have specified the fact that the renal insufficiency, which can occur after the mannitol administration, is related more to the preexisting high blood pressureor to the existence of a diabetes mellitus, than to osmolarity or to the mannitol doses. $(2,12$, 20, 25, 29)

Furosemide is an ansa diuretic, it is used in a dose of $10-40 \mathrm{mg}$, which is administered intravenously or as an initial dose of $0.5-1 \mathrm{mg} / \mathrm{Kgc}$; it also decreases the CSF production.

The combination of these two diuretics is more efficient and it requires the monitoring of the sanguine electrolytes (potassium).

Corticosteroids (dexamethasone) are efficient in the vasogenic brain edema as they repair the brain-blood barrier. A quantity of $4-20 \mathrm{mg}$ of dexamethasone is administered intravenously, and the effects are felt in a few hours. $(12,16,18,29)$

\section{Decrease in CSF secretion and excess}

The acetazolamide and corticosteroids reduce the production of cerebrospinal fluid, and they are used in order to reduce the CSF volume. Acetazolamide is a sulfonamide that specifically inhibits the carbonic anhydrase at the level of the renal tube, ciliary body, choroid plexus, and in the digestive mucous membrane. The acetazolamide administration in doses of $250-1000 \mathrm{mg} /$ day gradually reduces the CSF production; it is necessary to monitor the electrolytes and the sanguine $\mathrm{pH} .(3,5$, $7,11,28,31)$

A reduced CSF secretion also happens after the administration of mannitol and furosemide. 
The rapid removal of the CSF excess can be performed by means of a ventricular drainage during the intracranial pressure monitoring, which ensures the intracranial pressure control, or by means of an external ventricular drainage in emergency cases. The CSF drainage by lumbar puncture or by lumbar catheter is not used due to the risk of cerebral herniation. In the case of an idiopathic intracranial hypertension syndrome, the lumbar-peritoneal shunt is sometimes used, while, in the case of an obstructive hydrocephalus, ventricularperitoneal shunting systems may be used. $(3,6)$

\section{Maintaining a normal cerebral sanguine perfusion}

The sanguine arterial pressure increase is recommended in order to maintain an appropriate cerebral perfusion pressure when the monitoring reveals a significant increase in the intracranial pressure. The hypertensive therapy for the systemic blood pressure increase includes the administration of colloidal solutions, intravenous vasopressors, such as dopamine or phenylephrine. $(1,8,10,15,26)$

In the case of the intracranial hypertension syndrome in traumatic brain injury, the systemic arterial pressure may usually increase up to $150-170 \mathrm{~mm} \mathrm{Hg}$. In the case of decreased values of the cerebral perfusion pressure, sanguine pressure increasing measures can be applied even with the risk of an ICP increase as the purpose is to maintain the normal values of the cerebral perfusion pressure. $(3,5,6,9$, 10)

In the case of non-traumatic intracranial hypertension syndrome and in the absence of the cerebral hemorrhage, the blood pressure can increase up to $180 \mathrm{~mm} \mathrm{Hg}$.
Corresponding author:

A.St. Iencean

Emergency Hospital "N. Oblu" Iasi

andrei_steffan@yahoo.com

\section{References}

1. Adelson PD, Bratton SL, Carney NA, Chesnut RM, du Coudray HE, et al The use of barbiturates in the control of intracranial hypertension in severe pediatric traumatic brain injury. Pediatr Crit Care Med. 2003; 4: S49-52.

2. Adelson PD, Bratton SL, Carney NA, Chesnut RM, et al The role of cerebrospinal fluid drainage in the treatment of severe pediatric traumatic brain injury. Pediatr Crit Care Med. 2003, 4(3 Suppl): S38-9.

3. Adelson PD, Bratton SL, Carney NA, Chesnut RM, et al Use of hyperosmolar therapy in the management of severe pediatric traumatic brain injury. Pediatr Crit Care Med. 2003; 4(3 Suppl): S40-4.

4. Adelson PD, Bratton SL, Carney NA, Chesnut RM, et al Surgical treatment of pediatric intracranial hypertension. Pediatr Crit Care Med. 2003; 4(3 Suppl): S56-9.

5. Adelson PD, Bratton SL, Carney NA, Chesnut RM, et al The use of corticosteroids in the treatment of severe pediatric traumatic brain injury. Pediatr Crit Care Med. 2003; 4(3 Suppl): S60-4.

6. Adelson PD, Bratton SL, Carney NA, et al Critical pathway for the treatment of established intracranial hypertension in pediatric traumatic brain injury. Pediatr Crit Care Med. 2003; 4(3 Suppl): S65-7.

7. Allan R, Chaseling R. Subtemporal decompression for slit-ventricle syndrome: successful outcome after dramatic change in intracranial pressure wave morphology. Report of two cases. J Neurosurg. 2004; 101( Suppl): 214-7.

8. Battison C, Andrews PJ, Graham C, et al Randomized, controlled trial on the effect of a $20 \%$ mannitol solution and a $7.5 \%$ saline $/ 6 \%$ dextran solution on increased intracranial pressure after brain injury. Crit Care Med. 2005; 33(1): 196-202.

9. Berger S, Schwarz M, Huth R. Hypertonic saline solution and decompressive craniectomy for treatment of intracranial hypertension in pediatric severe traumatic brain injury. J Trauma. 2002 53(3): 558-63.

10. Coppage KH, Sibai BM. Treatment of hypertensive complications in pregnancy. Curr Pharm Des. 2005; 11(6): 749-57.

11. Cruz J, Minoja G, Okuchi K. Major clinical and physiological benefits of early high doses of mannitol for intraparenchymal temporal lobe hemorrhages with abnormal pupillary widening: a randomized trial. Neurosurgery. 2002, ; 51(3): 628-37. 
DOI: 10.2478/v10282-012-0017-y

12. Demchuk AM, Burgin WS, Christou I, et al. Thrombolysis in brain ischemia (TIBI) transcranial Doppler flow grades predict clinical severity, early recovery, and mortality in patients treated with intravenous tissue plasminogen activator. Stroke. 2001; 32: 89-93.

13. Diener HC, Ringelstein EB, von Kummer R, et al. Treatment of acute ischemic stroke with the lowmolecular-weight heparin certoparin: results of the TOPAS trial: Therapy of Patients with Acute Stroke (TOPAS) Investigators. Stroke. 2001; 32: 22-29.

14. Donnan GA, Davis SM. Surgical decompression for malignant middle cerebral artery infarction: a challenge to conventional thinking. Stroke. 2003; 34(9): 2307.

15. El-Watidy S. Bifrontal decompressive craniotomy in a 6-month-old infant with posttraumatic refractory intracranial hypertension. Pediatr Neurosurg. 2005; 41(3): 151-4

16. Figaji AA, Fieggen AG, Peter JC. Early decompressive craniotomy in children with severe traumatic brain injury.Childs Nerv Syst. 2003; 19(9): 666-73.

17. Fraser JF, Hartl R. Decompressive craniectomy as a therapeutic option in the treatment of hemispheric stroke. Curr Atheroscler Rep. 2005; 7(4): 296-304.

18. Georgiadis AL, Suarez JI. Hypertonic saline for cerebral edema. Curr Neurol Neurosci Rep. 2003; 3(6): 524-30

19. Gupta R, Connolly ES, Mayer S, Elkind MS. Hemicraniectomy for massive middle cerebral artery territory infarction: a systematic review. Stroke. 2004; 35(2): 539-43

20. Iencean St M A new classification and a synergetical pattern in intracranial hypertension. Medical Hypotheses, 2002; 58(2): 159-63.

21. Iencean St $M$ Brain edema - a new classification. Med Hypotheses. 2003; 61(1): 106-9.

22. Iencean St $M$ Ciurea $A V$ Intractranial Hypertension, Nova Science Publishers, New York,
2009.

23. Kontopoulos V, Foroglou N, Patsalas J, et al Decompressive craniectomy for the management of patients with refractory hypertension: should it be reconsidered? Acta Neurochir (Wien).2002; 144(8): 791-6.

24. Lee AG, Pless M, Falardeau J, et al The use of acetazolamide in idiopathic intracranial hypertension during pregnancy. Am J Ophthalmol. 2005; 139(5): 855-9.

25. Owler BK, Parker G, Halmagyi GM, Pseudotumor cerebri syndrome: venous sinus obstruction and its treatment with stent placement. J Neurosurg. 2003; 98(5): 1045-55.

26. Schneider GH, Bardt T, Lanksch WR, Unterberg A. Decompressive craniectomy following traumatic brain injury: ICP, CPP and neurological outcome. Acta Neurochir Suppl. 2002; 81: 77.

27. Shiozaki T, Nakajima Y, Taneda M, etc all. Efficacy of moderate hypothermia in patients with severe head injury and intracranial hypertension refractory to mild hypothermia. J Neurosurg. 2003; 99(1): 47-51.

28. Togay-Isikay C, Kim JY, Meads D, Tegeler C. Lumbar drainage affects transcranial Doppler pulsatility and waveforms in the presence of elevated intracranial pressure.Eur J Neurol. 2005; 12(5): 407-9.

29. Videtta W, Villarejo F, Cohen M, et al Effects of positive end-expiratory pressure on intracranial pressure and cerebral perfusion pressure. Acta Neurochir Suppl. 2002; 81: 93-7.

30. Watling CJ, Cairncross JG. Acetazolamide therapy for symptomatic plateau waves in patients with brain tumors. Report of three cases. J Neurosurg. 2002; 97(1): 224-6.

31.Woodworth GF, McGirt MJ, Williams MA, Rigamonti D. The use of ventriculoperitoneal shunts for uncontrollable intracranial hypertension without ventriculomegally secondary to HIV-associated cryptococcal meningitis. Surg Neurol. 2005; 63(6): 529531. 